\title{
Reference-dependent Analysis of Capital Structure and REIT Performance
}

\begin{abstract}
Using prospect theory, we develop a theoretical framework to examine the relationship between leverage and Real Estate Investment Trust (REIT) returns by introducing the concept of reference point. We postulate that firms' capital structure decisions are affected by target leverage (i.e., the reference point) as well as the observed leverage. Market conditions combined with firms' capital structure will put firms in either loss or gain domains, where firms behave differently. In general, the leverage-return relationship is positive in the gain domain and negative in the loss domain. Firms are then subject to asymmetric risk preference in different domains. Our empirical evidence shows strong support for the theoretical model. Compared to the conventional approach where only observed leverage is used, our model is more flexible and realistic in revealing the underlying structure of the leverage-returns relationship.
\end{abstract}

\section{Keywords:}

REITs performance; Capital structure; Behavioral finance; Prospect theory; Risk preferences

JEL Classification: G32, G02 


\section{Reference-dependent Analysis of Capital Structure and REIT Performance}

\section{Introduction}

A considerable amount of literature has investigated the relationship between leverage and returns (a measurement of firm performance) since Bhabdari (1988). Whether a consistent relationship exists between leverage and returns remains unclear. The findings from previous literature often vary greatly among sampling periods, sectors, or measurements of leverage. For example, using U.S. stock market data between 1962 and 1989, Fama \& French (1992) find that leverage and returns are positively related when market leverage is used, and the relationship is reversed when book leverage is adopted. Gomes and Schmid (2010) extend the sampling period to 2006, and find the leverage-returns relationship to be insignificant when book leverage is used in their analysis. No consensus has been reached regarding the reason for the mixed results.

This study considers a behavioral element that has been largely overlooked in the capital structure literature. Using prospect theory (Kahneman \& Tversky, 1979), we introduce the reference-dependence concept to the stock return model of Fama and French (1992) and apply the model in the Real Estate Investment Trust (REIT) sector. The challenges facing researchers when applying prospect theory is the lack of well-defined reference points and the over-reliance on laboratory experiments (see, for example, the discussions in Barberis, 2013). However, in financial settings, plausible reference points are easier to be identified (e.g., the risk-free rate in investment return analysis) and field data are more readily available in good quality and quantity. Consequently, prospect theory has been widely adopted to explain puzzles and anomalies in the finance literature, such as the low long-term average return on IPO stocks (Barberis \& Huang, 2008), equity premium puzzle (Benartzi \& Thaler, 1995) and disposition effect (Barberis \& Xiong, 2009). Building upon existing literature, we reconcile some puzzling results of leverage-return relationship by acknowledging reference-dependence and asymmetric risk preferences in firms' capital structure decisions.

The central idea of our paper is that firms' capital structure decisions are affected by target leverage (i.e., the reference point) as well as the observed leverage. Firms adjust their current leverage based on its deviation from the target leverage. Considering that target leverage is firm-specific, a given observed leverage can put a firm in either the over-leveraged or the under-leveraged position, depending on the value of the target leverage. Moreover, the cost of financing varies based on market conditions. Over-leveraged firms can enjoy the benefits of leveraging in up markets where capital is abundant, whereas they may suffer from the downside of leveraging when credits dry out in down markets. The opposite is true for under-leveraged firms. Consequently, firms may exhibit asymmetric risk 
preferences under different combinations of market conditions and leverage positions. The relationship between return and leverage should not be simply identified as positive, negative, or insignificant unconditionally. The relationship should be studied by considering relative leverage positions (over- or under-leveraged) and market conditions (up or down market). Based on prospect theory, we develop a model to capture this non-linear and asymmetric relationship between leverage and return. Compared to the conventional approach where only observed leverage is used, our model is more flexible and realistic in revealing the underlying structure of the leverage-returns relationship. It is also a potential solution to reconcile conflicting findings in the literature.

Our theoretical model is validated with data from the real estate investment trust (REIT) sector ${ }^{1}$. Most of the existing leverage-returns studies exclude the real estate sector due to its unique corporate tax requirements. The relationship between capital structure and REIT performance remains an under-researched area. However, stylized facts indicate that the level of debt-financing affects REITs performance significantly (Sun, Titman, \& Twite, 2015). We derive the theoretical model with the REITs sector specifically in mind in order to bridge this gap in the literature.

Specifically, we choose the REIT sector to test our theoretical model for the following reasons. First, to meet the special dividend payout requirement, REITs have to raise capital more frequently to ensure sufficient cash flow (Devos, Spieler, \& Tsang, 2014; Hardin \& Wu, 2010). Thus, capital structure decisions are particularly important to capital-intensive REITs. Second, REITs is one of the few industries where the underlying assets are traded in secondary markets (Boudry, Kallberg, \& Liu, 2010). Hence the REITs sector is more likely to be closely linked to local market conditions and underlying assets performance. This makes REITs an ideal and unique sector to test our theoretical model. Last, investors have been increasingly aware of the benefits of REITs as a vehicle to tap in the fast-growing real estate markets around the world. Between 2005 and 2014, the S\&P REITs index shows a gain of $259 \%$ (or an annualized growth rate of $10 \%$ ) compared to a $221.39 \%$ (or an annualized growth rate of $8.27 \%$ ) increase in the S\&P 500 index. In November 2014, S\&P Dow Jones Indices and MSCI Inc. decided to create a new headline sector for real estate. Equity REITs and listed real estate companies will be moved from the Financial Sector to the newly created Real Estate Sector ${ }^{2}$. With all the interesting developments in the REIT sector, research on the relationship

\footnotetext{
1 Evidences show that REITs behave like stocks in many ways (see, for example, Case, Yang, \& Yildirim, 2012; Glascock, Lu, \& So, 2000). Therefore, our findings not only shed light on capital structure decisions in this unique and under-researched sector, but also can be generalized beyond the US REIT industry. We tested our models by using US stock market data from 1998 to 2013. The results (not presented here for the sake of brevity but available from the authors upon request) are consistent with findings from the REIT sector.

2 https://www.reit.com/investing/reit-basics/reit-industry-timeline\#55.
} 
between capital structure and REIT performance will benefit all stakeholders involved. This statement is particularly true given the fact that existing studies primarily focus on REIT capital structure determinants (Alcock, Steiner, \& Tan, 2014; Ertugrul \& Giambona, 2010; Harrison, Panasian, \& Seiler, 2011) or the relationship between REIT capital structure and corporate governance (Alcock, Glascock, \& Steiner, 2013; Striewe, Rottke, \& Zietz, 2013). The relationship between capital structure and REIT performance has largely been overlooked.

Empirical evidence provides strong support for our theoretical model. By testing the three hypotheses on target leverage formation and leverage-returns relationship, we conclude that 1) firm characteristics are useful in the estimation of target leverage; 2 ) reference point (or target leverage) plays an important role in the leverage-returns relationship; and 3) firms are subject to asymmetric risk preference in loss and gain domains. Specifically, firm-specific and time-varying target leverage determines a firm's leverage position. Such a situation, combined with market conditions, will put the firm in either loss or gain domains, where firms behave differently. In general, the effect of leverage on returns is positive in the gain domain and negative in the loss domain. Moreover, firms are risk averse in gain domain but risk seeking in loss domain. As an application of behavioral economics in capital structure decisions, this paper considers the role of reference point and the heterogeneity of firm behaviors in the loss and gain domains. We also verify the robustness of the findings by considering alternative measurements of observed leverage. Overall, our model is not sensitive to alternative definitions of leverage.

The remainder of this paper is organized as follows: the theoretical model is presented and the testable hypotheses are derived in Section 2. The empirical implementation of the theoretical framework is discussed in Section 3. Discussions on the empirical findings are given in Section 4, followed by conclusions provided in Section 5.

\section{Theoretical Framework and Testable Hypotheses}

This study not only investigates the formation of a reference point in capital structure decisions, but also more importantly determines the way a reference point operates in the leverage-returns relationship.

The topic of capital structure decisions can be traced back to Modigliani and Miller's first proposition (Modigliani \& Millier, 1958). They proposed that firm value should be irrelevant to its capital structure decisions in the absence of taxes, information asymmetry, transaction costs, and bankruptcy costs, among others. The assumptions above are strong with respect to the imperfect market conditions in reality. Subsequent research has tested this proposition vigorously 
by answering two fundamental questions. First, is a capital structure decision relevant to firm performance? If yes, then second, what effect should leverage have on firm performance?

Conventionally, researchers use observed leverage as a factor in investigating the leverage-returns relationship (Bhabdari, 1988; Fama \& French, 1992; George \& Hwang, 2010; Gomes \& Schmid, 2010). Specifically,

$R_{i, t+1}=f\left(L_{i, t} \mid \boldsymbol{C}_{i, t}\right)$

where $R_{i, t+1}$ is the shareholders return of firm $i$ at time $t+1, L_{i, t}$ is the observed leverage of firm $i$ at time $t$, and $\boldsymbol{C}_{i, t}$ is a vector of control variables.

Bhabdari (1988) is the first to empirically test the relationship between leverage and return using the above-stated model. Until now, most of the available empirical evidence is inconsistent with the irrelevance proposition. The violation of its friction-free market environment assumption determines that firm performance depends on the way firms finance their operations. However, the exact relationship between leverage and returns is less clear (Gomes \& Schmid, 2010). Findings often vary greatly among sampling periods, sectors, or measurements of leverage (Bhabdari, 1988; Fama \& French, 1992; George \& Hwang, 2010; Gomes \& Schmid, 2010; Livdan et al., 2009; Penman, Richardson, \& Tuna, 2007; Trigeorgis \& Lambertides, 2014). To solve this puzzle, some researchers consider firms' leverage targeting behaviors in the basic model by Bhabdari (1988). It has been established in the capital structural literature that firms gradually adjust their capital structure towards an optimal leverage (e.g., Chang \& Dasgupta, 2009; Flannery \& Rangan, 2006). Consequently, capital structure decisions should be based on the deviation of a firm's leverage from its target leverage. A recent study by Caskey et al. (2012) introduce this concept into the leverage-return relationship studies by considering 'excess leverage', which is essentially the deviation of observed leverage from the target leverage. This dynamic view of capital structure offers plausible explanation to the puzzling findings in the literature.

We extend the work of Caskey et al. (2012) by formulating a conceptual framework for the analysis of leverage deviation based on prospect theory. Caskey et al. (2012) consider linear relationship between excess leverage and returns only. We relax this assumption by deriving a flexible theoretical model from prospect theory (Kahneman \& Tversky, 1979). We make use of the value function in prospect theory to capture the non-linear and asymmetric relationship between leverage and returns. The proposed theoretical model recognizes the important role of target leverage in capital structure decisions. More importantly, it provides a flexible framework to derive testable hypotheses in empirical 
studies.

Prospect theory improves the explanatory power of conventional economic theories, especially when considering consumer preference and status quo (Kahneman \& Tversky, 1979). Prospect theory introduces a reference point to the decision making process. Under prospect theory, individuals do not value their gains and losses based on global or globally available wealth but rather take stock of these values relative to an individually specific reference point. Without losing any generality, the relationship can be described with Equation (2) and illustrated in Figure 1.

$v(X)= \begin{cases}(X-r)^{a} & X \geq r \\ -\lambda(r-X)^{c} & X<r\end{cases}$

where $v(X)$ is the value function based on outcome $X$, and $r$ is the reference point. When $X$ is greater than $r$, individuals enter the gain domain; otherwise, they fall in the loss domain. $\lambda$ is the loss aversion coefficient. $\lambda>1$ reflects that individuals' value function in the loss domain is steeper than that in the gain domain (i.e., loss aversion). $a$ and $c$ are diminishing sensitivity coefficient in the gain and loss domains, respectively. $a<1$ and $c<1$ indicate that the marginal gains and losses diminish with the distance between $X$ and $r$. Individuals are risk averse in the gain domain but risk seeking in the loss domain.

\section{[Insert Figure 1 Here]}

Under prospect theory, firms should not evaluate shareholders' returns based on globally observed leverage but should instead re-assess their capital structure relative to firm-specific reference points (i.e., firms' target leverage). The introduction of reference point offers two advantages. First, it facilitates the determination of firms' relative positions (over- or under-leveraged) of observed leverage to their target. The magnitude of the leverage deviation can be quantified subsequently. Second, the reference point can be combined with market conditions to determine whether a firm is in a loss or gain domain. We believe that firms make different adjustment decisions on capital structure in the loss and gain domains. Considering that the cost of capital is determined by market liquidity (Subrahmanyam, 2007), an up market is reasonably assumed to place under-leveraged firms in the loss domain. The cost of financing is relatively low under such a market condition. Thus, under-leveraged firms may forgo investment opportunities when they are less funded. Similarly, a down market places over-leveraged firms in the loss domain. With the relatively high cost of capital in down market, over-leveraged firms are bonded with collateral constraints (Livdan et al., 2009), which may cause them to suffer financial distress and bankruptcy risks. In summary, adjustment cost varies according to market 
condition, which ultimately determines that firms will not behave identically in these two domains. The complex relationship between leverage and returns is further illustrated in Figure 2.

[Insert Figure 2 Here]

Accordingly, Equation (1) can be re-written as follows:

$R_{i, t+1}=f\left(\left|L_{i, t}-r_{i, t}\right| \mid C_{i, t}\right)$

where $r_{i, t}$ is the reference point of firm $i$ at time $t$, which is also the target leverage; and $R_{i, t+1}, L_{i, t}$, and $\boldsymbol{C}_{i, t}$ remain as previously defined.

The introduction of a reference point $r_{i, t}$ in Equation (3) establishes the role of the target leverage in capital structure decisions. A firm's capital structure position is determined by two factors: leverage deviation from the target leverage (i.e., $\left.\left|L_{i, t}-r_{i, t}\right|\right)$, and market conditions. The marginal effect of leverage deviation is given in the table below.

\section{[Insert Table 1 Here]}

We allow $r_{i, t}$ to vary among firms and over time. Although firms tend to have a stable leverage in the long run (e.g., two decades or longer), the unobserved firm specific factors can explain about $60 \%$ of the variation in leverage only (Lemmon, Roberts, \& Zender, 2008). Other time-varying and cross-section varying factors, such as profitability and growth potential, significantly affect capital structure decisions, albeit to a lesser extent. More recent studies such as DeAngello \& Roll (2015) question the stability of cross-sectional leverage. Also, as emphasized by Korteweg (2010), firms adjust their leverage dynamically. In the short term, the optimal leverage (i.e., $r_{i, t}$ ) does not necessarily equal the long-term target ratio because adjustment cost is not constant over time and across firms.

Existing empirical studies have confirmed the presence of firms' targeting behavior regarding capital structure decisions. Examples can be found in the work of Chang and Dasgupta (2009), Gaud, Jani, Hoesli, and Bender (2005) and Graham and Harvey (2001). In addition, Flannery and Rangan (2006) propose that leverage target should depend on a series of a firm's characteristics related to the costs of financial distress and the benefits from tax shields. Moreover, Korteweg (2010) summarizes the variation of leverage targets with firm characteristics, especially firm size and profitability. Furthermore, in a financial context, Baucells et al. (2011) investigate the formation of reference points by decision makers by weighting sequences of market information. Building upon theoretical and empirical findings in the literature, we propose that the firm-level target leverage 
$r_{i, t}$ can be measured as a combination of firm-level characteristics $\gamma_{0}+\boldsymbol{\gamma} \boldsymbol{\alpha}_{i, t-1}$, where $\boldsymbol{\alpha}_{i, t-1}$ is a group of characteristics for firm $i$ at time $t-1, \gamma$ is the weighting vector, and $\gamma_{0}$ is the constant term that captures the long-term, time-invariant component of leverage.

We use the partial adjustment model proposed by Flannery and Rangan (2006) to obtain reliable estimates of $\gamma_{0}, \gamma$ and ultimately the estimated value of $r_{i, t}$. Although firms are trying to maintain their leverage at the target level, adjustment costs may prevent them from doing so. The partial adjustment model allows us to estimate how firm's capital structure partially adjusts toward its target within each time period. Each year, the typical firm takes positive steps to close the gap between its actual leverage and its expectation with a certain adjustment speed, as described below:

$L_{i, t}-L_{i, t-1}=\beta\left(r_{i, t}-L_{i, t-1}\right)+\varepsilon_{i, t}$

where $L_{i, t}$ and $L_{i, t-1}$ are the observed leverage of firm $i$ at time $t$ and $t-1$, respectively, and $\beta$ is the speed of adjustment showing the speed at which firms converge toward their expectations. $\varepsilon_{i, t}$ is the error term.

In substituting the measurement of $r_{i, t}$ into equation (4) we can obtain:

$L_{i, t}=\beta \gamma_{0}+(\beta \gamma) \boldsymbol{\alpha}_{i, t-1}+(1-\beta) L_{i, t-1}+\varepsilon_{i, t}$

In essence, leverage is determined by a weighted average of the target leverage and observed leverage, with the weights determined by the adjustment rate towards the target leverage. $r_{i, t}$ can then be calculated by using the estimates of $\gamma$ and $\gamma_{0}$ in Equation (5).

Once the value of the target leverage level is determined, Equation (3) can verify the relationship between leverage and returns with a reference point. Specifically, Equation (3) can be the basis for deriving the following hypotheses:

Testable hypothesis 1: Firm-level characteristics determine the formation of target leverage.

If this hypothesis is true, then the estimation coefficients of $\beta$ and $\gamma$ in Equation (5) are significantly different from zero. As a result, firm-level characteristics do affect reference point, or target leverage.

Testable hypothesis 2: A reference point matters in the relationship between leverage and returns. 
In order to test this hypothesis, $r_{i, t}$ will be used to estimate $\frac{\partial R_{i, t+1}}{\partial\left|L_{i, t}-r_{i, t}\right|}$ under various combinations of market condition and leverage position. Results can be used to verify the relationship described in Table 1.

Once a reference point is determined, firms are then placed into either gain domain (i.e., the marginal effect of leverage deviation, $\left|L_{i, t}-r_{i, t}\right|$, is positive) or loss domain (i.e., the marginal effect of leverage deviation, $\left|L_{i, t}-r_{i, t}\right|$, is negative). We expect that firms' capital structure decisions are not uniform in the two domains, as illustrated in Figure 2. A final hypothesis is derived as follows.

Testable hypothesis 3: Firms are risk averse in gain domain but risk seeking in loss domain when making capital structure decisions.

In order to test this hypothesis, an appropriate functional form will be adopted to verify the relationship between leverage deviation and return in Figure 2. As illustrated in Section 3, we include leverage deviation and its quadratic term in Equation (3). If the coefficient estimate is positive for leverage deviation and negative for its quadratic term in gain domain, we can conclude that firms are risk averse in gain domain when adjusting to target leverage. On the other hand, if firms are risk seeking when making capital structure decisions, we expect that the coefficient estimate is negative for leverage deviation and positive for its quadratic term. This relationship should hold true for both up and down market.

\section{Empirical Implementation}

We use REITs in North America as an example to test the proposed theoretical framework. The data are collected from WRDS and SNL database ${ }^{3}$ (SIC code: 6798). They cover North American equity REITs from 1993 to 2013. After removing missing values, outliers, and firms with less than two years' financial statement, 2,342 firm-year observations are retained. We first form estimations of target leverage for each firm in all periods, which are subsequently used to verify the role of leverage deviations on REIT performance.

\subsection{Target leverage estimation}

The dependent variable in Equation (5) is the observed leverage ratio of firm $i$ at time $t$. It is defined as the ratio of book value of total debt (i.e., debt in current liabilities plus long-term debt) to market value of assets (i.e., total debt plus

\footnotetext{
3 Monthly stock returns are from the Center of Research in Security Prices (CRSP) database. Financial statement data are collected from the Compustat Industrial Annual database. REITs characteristics variables are obtained from SNL.
} 
closing stock price of each fiscal year times number of outstanding common shares).

The independent variables include one-period lagged observed leverage and a set of firm-level characteristics. Firm-level characteristics are subsequently divided into two groups: traditional capital structure determinants and REIT attributes. We include firm size, profitability, growth potential, and asset tangibility as traditional capital structure determinants. As pointed out by Cashman et al. (2013), these four factors are the most robust predictors of leverage. The consensus in the literature is that leverage is positively related to firm size and asset tangibility but negatively related to profitability and growth potential. Details of variable definitions, formulas, data sources, and references can be found in Table 2.

The choice of REIT attributes is largely based on the work of Cashman et al. (2013) and Harrison et al. (2011). Specifically, four aspects of REITs attributes are considered as follows:

Liability Structure: The financing choice of REITs is influenced by their existing liability structure (Brown \& Riddiough, 2003). We consider the role of secured debt and rated debt in our models. SECURED is defined as the ratio of secured debt to total debt. Companies with a higher proportion of secured debt tend to finance by issuing equity. Otherwise, additional public debt is preferred (Brown \& Riddiough, 2003). Hence, the coefficient estimation of SECURED is expected to be negative. RATED is a dummy variable that equals one if a REIT has an S\&P long-term issuer credit rating. Companies with a credit rating are associated with either low transaction cost or high transparency. Mixed findings are found regarding its effect on financing decisions (Boudry et al., 2010; Cashman et al., 2013; Harrison et al., 2011).

Firm Age: Firm age is defined as number of years since the initial public offering of a REIT. It is associated with the level of information asymmetry. Older firms are likely to upgrade their use of public debt because the market knows more about them over time. Hence, the expected sign for $A G E$ is positive, although insignificant estimates are not uncommon in the literature (see for example Harrison et al., 2011).

Operating Strategy: Operating strategy is captured by activities such as repurchase and dividend payout. $R E P$ is a continuous variable that represents the amount of share repurchases in each fiscal year (Boudry, Kallberg, \& Liu, 2013) 4 Repurchasing common shares will reduce the equity level of a REIT, which is

${ }^{4}$ When Common Share Repurchases information is missing, we set the corresponding REP value to be zero. 
considered as a positive signal in the marketplace ${ }^{5}$. Additionally, EXCESS_DIV reflects companies' dividend policies. It is defined as the amount of common stock dividend payout minus $90 \%$ of pretax income, divided by total assets. Pecking order theory (Myers \& Majluf, 1984) predicts that EXCESS_DIV would have a positive loading.

Market timing behavior: PRICE_NAV captures any market timing behaviors. According to market timing theory, REITs with a high price to Net Asset Value (NAV) are more likely to raise capital through equity (Boudry et al., 2010; Harrison et al., 2011; Ooi, Ong, \& Li, 2010).

\section{[Insert Table 2 Here]}

\subsection{Leverage deviation and the leverage-returns relations}

To verify the role of target leverage in Equation (3), we extend the model of Fama \& French (1992) and Fama \& French (2008) as follows:

$R_{i, j}=\theta_{0}+\theta_{1} L_{i, t}+\sum_{k=1}^{l} \boldsymbol{\tau}_{k} \boldsymbol{C}_{k, i, t}+\varepsilon_{j}$

where $R_{i, j}$ is the monthly stock return, and $\boldsymbol{C}_{k, i, t}$ is a vector of control variables including measurements of market capitalization, book to market ratio of equity, momentum, and underlying asset performance. The monthly returns between July (i.e., $j=7$ ) in calendar year $t+1$ to June (i.e., $j=6$ ) in calendar year $t+2$ are matched with annual financial data ending in calendar year $t$. The definition and calculation of control variables are both described in details below and summarized in Table 3.

Market capitalization is calculated as the natural logarithm of the market value of the outstanding common shares of firms. Book to market ratio of equity is measured as the natural logarithm of the ratio of the book value of equity and the market value of equity. Momentum return is calculated on a monthly basis. For each of the $R_{i, j}$, the corresponding monthly momentum is an 11-month compounded return from month $j-12$ to month $j-2$. We include this factor to control for the momentum anomaly (i.e., a positive relationship between past returns over the last year and future returns over the next few months). Similar to Fama \& French (2008), we omit month $j-1$ when calculating momentum return to avoid the influence of a negative correlation between the return of month $j$ and $j-1$ (Jegadeesh, 1990). NOI_NPI captures underlying asset performance. It is

\footnotetext{
5 Existing studies use both continuous variable of share repurchases (i.e., the amount of repurchases) and dummy variables to measure REITs share repurchases (see, for example, Boudry et al., 2013; Harrison et al., 2011). In this study, our results are quantitatively identical when using continuous variables and dummy variable of share repurchases.
} 
calculated as the ratio of net operating income to net property investment. This control variable is designed to capture any REITs specific characteristics because REITs is one of the few industries where underlying assets are traded in secondary markets (Boudry et al., 2010). Therefore, the performance of REITs underlying assets has a potential influence on its stock performance. If one unit of REITs property investment generates higher operating income, it will be considered as a positive signal to investors and consequently have a positive loading on REITs return. This approach is also adopted in Harrison et al (2011)'s empirical work.

We first extend Equation (6) by replacing observed leverage $L_{i, t}$ with Deviation, a measurement of leverage deviation from the target leverage. Deviation is calculated as $\left|L_{i, t}-r_{i, t}\right|$.

$R_{i, j}=\theta_{0}+\theta_{1}$ Deviation $+\sum_{k=1}^{l} \boldsymbol{\tau}_{k} \boldsymbol{C}_{k, i, t}+\varepsilon_{j}$

Equation (7) provides a crude test for reference point dependence in capital structure decision analysis. $\theta_{1}$ caputures the effect of leverage deviation on returns. However, this model specification overlooks the dynamic nature of asymmetric risk preferences as described in our conceptual framework. Leverage deviation has different effects on returns according to their leverage position (under- or over-leveraged) and market condition (up or down market), as shown in Table 1. Subsequently, Equation (7) is revised to obtain Equation (8) as follows:

$$
\begin{aligned}
R_{i, j}= & \theta_{0}+\theta_{1} \text { Deviation }+\theta_{2} \text { Deviation }^{2}+\theta_{3} \text { Deviation } * \omega \\
& +\theta_{4} \text { Deviation }^{2} * \omega+\theta_{5} \omega+\sum_{k=1}^{l} \boldsymbol{\tau}_{k} \boldsymbol{C}_{k, i, t}+\varepsilon_{j}
\end{aligned}
$$

where $\omega$ equals one for up markets or zero otherwise. The inclusion of Deviation $^{2}$ allows the test of risk preferences. The interaction terms between Deviation, Deviation ${ }^{2}$, and $\omega$ capture the moderating effect of market condition on the leverage-returns relationship. Equation (8) is estimated using over-leveraged (when $L_{i, t}>r_{i, t}$ ) and under-leveraged (when $L_{i, t}<r_{i, t}$ ) subsamples separately. $\theta_{1}, \theta_{2}, \theta_{3}$, and $\theta_{4}$ combined provide estimates of marginal effect of leverage deviation in Table 1 . If Hypothesis 2 is true, the expected sign for $\theta_{1}$ is negative in a down market, and the expected effect of $\theta_{1}+\theta_{3}$ is positive in an up market for over-leveraged firms. If hypothesis 3 is true, the expected sign of $\theta_{2}$ is positive for over-leveraged firms in a down market, and the value of $\theta_{2}+\theta_{4}$ is expected to be negative in an up market. The opposite is true for under-leveraged firms.

[Insert Table 3 Here] 


\section{Findings and Discussions \\ 4.1 Target leverage estimation}

Table 4 shows the descriptive statistics of the observed leverage and firm-level characteristics. Despite differences in sampling period and sample size, our sample shows similar statistical characteristics with those of other samples used in existing REIT capital structure literature. More specifically, the mean observed leverage of REITs over the study period is 0.461 , which indicates that on average the total debt counts for more than $45 \%$ of the total assets of REITs ${ }^{6}$. Around $40 \%$ of the REITs in our sample have outstanding rated debt, and two-thirds of the total debt are secured debt. The characteristics of other control variables, such as market-to-book ratio and total assets, are largely in line with the literature.

\section{[Insert Table 4 Here]}

As many of the capital structure determinants (i.e., $\boldsymbol{\alpha}_{i, t-1}$ in Equation 5) listed in Table 2 are highly correlated, we follow the common practice (Lettau \& Ludvigson, 2001, 2004; Lizieri, 2013; Paiella, 2009) to orthogonalize these variables before estimating Equation (5). We consider three model specifications: an Ordinary Least Square (OLS) model as the benchmark, a Least Square Dummy Variable (or fixed effect model, henceforth FE) model, and a system generalized method of moments (GMM) model ${ }^{7}$. The best estimates from these three model specifications are subsequently used to calculate the firm-level target leverage $r_{i, t}$. The coefficient estimates from these three models are given in Table 5.

The OLS model (Model 1 in Table 5) includes year dummy variables but does not consider firm fixed effect. Although the model has a good adjusted R square and as-expected coefficient estimates, it does not provide an accurate estimation of adjustment speed (i.e., $\beta$ in our model), which is an essential input in our next step of analysis. More specifically, the OLS model suffers from measurement errors and endogeneity because of simultaneity between the dependent variable and leverage ratio. The system GMM method (Blundell \& Bond, 1998) is employed to address these issues. Following the empirical implementation in Blundell and Bond (1998), Flannery and Rangan (2006), Lemmon et al. (2008), and Flannery \& Hankins (2013), we then incorporate firm fixed effect by using a conventional FE method (Model 2) and a system GMM method (Model 3). Our findings are

\footnotetext{
${ }^{6}$ In comparison, REITs debt levels are higher than the general firms. In our sampling period, the mean leverage level for the general firms (excluding financial companies) is approximately $31 \%$.

7 Unlike standard parametric methods such as OLS, GMM does not make assumptions about the distributional properties of variables. The GMM estimators are known as the most consistent and efficient one in all moment-based estimators. More technical details about this method can be found in Hansen (1982).
} 
consistent with econometric theory predictions and other existing empirical findings by showing that the speed of adjustment from the GMM model lies between the estimates obtained by the OLS and FE models (See Table 5).

Although the use of FE or GMM method does not affect the estimation of the target leverage, the coefficient estimates of adjustment speed (i.e., $\beta$ in Equation 5) change notably in Model 2 and Model 3. The estimated adjustment speed $\beta$ tends to be biased downward by the OLS method but biased upward in FE models, whereas system GMM offers more precise estimates (see for example Blundell \& Bond, 1998; Flannery \& Hankins, 2013). In Table 5, the estimation of $\beta$ from Model 3 is located between the estimations obtained from Model 1 and Model 2. The result is in line with existing studies. Consequently, the calculation of the reference point and the discussions below are based on the coefficient estimations from Model 3.

\section{[Insert Table 5 Here]}

In Model 3, the determinants of target leverage include traditional capital structure determinants, such as profitability and growth, as well as the specific attributes of REITs such as rated debt, firm age, excess dividend and price to NAV. All significant variables in Model 3 are directionally consistent with ex ante expectations. Based on Model 3, the target leverage estimates, and subsequently the three leverage deviation measurements (i.e., Deviation, Over-leverage, and Under-leverage) to be used in the next step of our analysis, are obtained.

\subsection{Leverage deviation and the leverage-returns relations}

As Korteweg (2010) suggests, imperfect market environment drives firms away from their target leverage levels. This point is confirmed in our data. In Figure 3, the annual average deviation from the target leverage ranges from $-32 \%$ to $25 \%$ in our sampling period. The deviation from the target leverage is obviously not time-invariant. The non-frictionless market can also generate cross-sectional heterogeneity, which means that the deviation is not cross-sectionally invariant. This fact can be reflected by the standard deviation of Deviation calculated in each year (i.e., the solid bars in Figure 3 using the right axis). The values are generally above $10 \%$ for most of the years in our sampling period, suggesting that the deviation from the target leverage varied significantly among firms within each year. The two pieces of evidence combined make a strong case for the time- and firm-varying nature of leverage deviation.

\section{[Insert Figure 3 Here]}

We then explore the correlation among the variables included in Equations (6), 
(7), and (8) as shown in Table 6. The correlation between Deviation and observed leverage is low (i.e., 0.016), which is not surprising because Deviation does not reflect the direction of the deviation from the target leverage (i.e. over- or under-leveraged). The absolute values of correlation coefficients between observed leverage and the new leverage measurements (i.e., over-leverage and under-leverage) are above 0.30. Meanwhile, the correlations between the three leverage deviation measurements and the control variables (i.e., market capitalization, book to market ratio of equity, momentum, and NOI_NPI) are small. Hence, multi-collinearity will not be a concern.

\section{[Insert Table 6 Here]}

To test hypotheses 2 and 3, Equation (6) to Equation (8) are estimated by using observed leverage $\left(L_{i, t}\right)$, deviations from the target leverage (Deviation), and leverage position (Over-leverage and Under-leverage), respectively, combined with market conditions. The result is 14 models in three groups, as shown in Table 7 (equation 6 and 7) and Table 8 (equation 8), respectively. All models are estimated using the GMM method.

Model (1) to Model (5) in Table 7 are used as the base models in the analysis of the leverage-returns relationship. The coefficient of market leverage is significant and positive, which is in line with the existing literature (Bhabdari, 1988; Fama \& French, 1992; Gomes \& Schmid, 2010; Trigeorgis \& Lambertides, 2014). However, the explanatory power of market leverage is reduced significantly when we successively control for market capitalization (Model 2), book to market ratio of equity (Model 3), momentum (Model 4), and NOI_NPI (Model 5). The effect of observed leverage has been absolved by market capitalization and/or book to market ratio of equity. Similar evidence regarding the limitations of using observed market leverage has been documented by Gomes and Schmid (2010).

With these considerations in mind, we estimate Equation (7) by replacing observed leverage with Deviation, which is a measurement of leverage deviation from the target leverage. This step is a crude check of the presence of reference points in capital structure decisions. The results are labeled Model (6) to Model (10) in Table 7. Contrary to the findings in Model (1) to (5), the effect of Deviation is not reduced significantly by the inclusion of market capitalization, book to market ratio of equity, momentum, and NOI_NPI. The significant and positive loading of Deviation confirms the role of target leverage (i.e., a reference point) in the leverage-returns relationship, and it suggests that Deviation is less sensitive to the inclusion of control variables. This result is an improvement of the base models. 
However, the specifications of Model (6) to Model (10) overlook the dynamic adjustment process, as described in our conceptual framework. This issue is reflected by the unexpected positive sign of Deviation in all four models. In theory, any deviation from the target leverage should be undesirable, and consequently the coefficient of Deviation should be negative. However, leverage deviation may have different effects on returns based on their leverage position (under- or over-leveraged) and market condition (up or down market). As captured by Hypothesis 2 and 3, the combined effect of both reference dependence and risk preference moderates the relationship between leverage and returns. Failure to control for these effects may result in biased coefficient estimates. To address this issue, Model (10) in Table 7 is re-estimated by splitting the whole sample into the over-leveraged and under-leveraged sub-samples and by adding quadratic terms of Deviation to capture any non-linear relationship between leverage deviation and returns. As reported in Model (1) and Model (3) in Table 8, considering leverage position alone is not sufficient, as coefficient estimates of Deviation and Deviation $^{2}$ are counter-intuitive in both models. The two models are further extended by including interaction terms of a market condition dummy variable, and the resultant models are labeled Model (2) and Model (4) in Table 8.

\section{[Insert Table 8 Here]}

Model (2) and (4) in Table 8 are the empirical realizations of Equation (8). The coefficient estimates of $\theta_{1}, \theta_{2}, \theta_{3}$, and $\theta_{4}$ are used to calculate the marginal effect of leverage deviation. As shown in Table 9, the estimations are consistent with our expectation in Table 1 . A reference point matters in the relationship between leverage and returns. Once a reference point is determined, firms are then placed into either gain or loss domain. As described in our theoretical model, over-leveraged firms find themselves in the gain domain in an up market (i.e., $\widehat{\theta}_{1}+\widehat{\theta}_{3}>0$ ), and in the loss domain during market downturns (i.e., $\hat{\theta}_{1}<0$ ). The opposite effect (i.e., $\left.\hat{\theta}_{1}+\hat{\theta}_{3}<0\right)$ in up markets and $\left(\hat{\theta}_{1}>0\right)$ in down markets, can be found for under-leveraged firms.

The estimated value of $\theta_{2}$ and $\theta_{4}$ can be used to identify firms' risk preference at different market conditions. Our results suggest that firms are risk averse in gain domain but risk seeking in loss domain. Specifically, under-leveraged firms are risk-averse in down markets (i.e., $\hat{\theta}_{2}<0$ ) and risk-seeking in up markets (i.e., $\hat{\theta}_{2}+\hat{\theta}_{4}>0$ ). For example, with higher financing cost in down markets, firms that choose lower level of debt overhang is risk-averse because they are trying to minimize financial distress or bankruptcy risk. An asymmetric risk preference (i.e., $\left.\hat{\theta}_{2}>0\right)$ in down markets and $\left(\hat{\theta}_{2}+\hat{\theta}_{4}<0\right)$ in up markets, can be found for over-leverage firms as well. The findings are also consistent with the prediction 
based on the notion of diminishing sensitivity, which is the foundation of risk-seeking and risk-averse preferences in loss and gain domains respectively.

\section{[Insert Table 9 Here]}

We find evidence to support the three testable hypotheses based on the proposed theoretical model. Target leverage, which is determined by firm-level characteristics, plays an important role as reference point in the leverage-returns relationship. Subsequently, firms are placed into either gain domain or loss domain under various combinations of leverage positions and market conditions. The deviation of observed leverage from its target leverage level affects firm returns significantly. When adjusting to target leverage, firms are found to be risk averse in gain domain but risk seeking in loss domain.

We investigate the robustness of these empirical findings by adopting different measurements of observed leverage (i.e., $L_{i, t}$ in Equation 5). We have considered book leverage and long-term leverage as alternative definitions of observed leverage. Regression output and discussions can be found in Tables A1 and A2 in the Appendix. In summary, the use of firm characteristics for target leverage estimation is an important step in our theoretical model. The firm-level characteristics included in our theoretical model provide a significant and robust estimation of target leverage across all three leverage measurements (see Table A1); the estimation of Equation (5) is not sensitive to the definition of leverage, as shown in Table A2. Although empirical results vary across differently observed leverage measurements, they all support our theoretical model ${ }^{8}$.

\section{Conclusions}

This study proposes a reference-dependent model to examine the relationship between a firm's decisions on capital structure and its performance. The conventional approach only considers observed leverage and overly simplifies the relationship between leverage and returns. Specifically, leverage is related to returns unconditional of firms' relative leverage position and market conditions. This assumed relationship inevitably gives rise to inconclusive findings as prevalent in the literature. In reality, the identified leverage-returns relationship varies greatly among sampling periods, sectors, or measurements of leverage.

\footnotetext{
8 We also checked if our results are sensitive to structural break around the last financial crisis. . The average estimated target leverage is significantly different from the corresponding industrial median in our sampling period (two-sample t-test statistics are all significant at the $5 \%$ level). This pattern is consistent before and after the financial crisis. We did not estimate the models in Tables 6 - 8 by splitting the sample into beforeand after-crisis subsamples, because the after-crisis subsample is not large enough for GMM estimation.
} 
By treating the firm-specific target leverage as a reference point, our model improves upon conventional models in two ways. First, with a reference point clearly defined, the relative position of the observed leverage to its target can be determined. Subsequently firms are classified as either over- or under-leveraged. Second, and more importantly, firms can be placed in either a loss or gain domain, which depends not only on the above-mentioned relative position (i.e., over- or under-leveraged) but also on the market condition (i.e., boom or bust). Under the assumption that leverage is positively related to returns in the gain domain and negatively related to returns in the loss domain, one can analyze and predict firms' returns accordingly. More importantly, firms are subject to asymmetric risk preferences under different domains. Our framework clearly shows that observed leverage alone is not sufficient to support the analysis of the leverage-returns relationship because it is incapable of determining the domain that a firm is located. A complete analysis of this relationship would require a combination of the observed leverage and target leverage. The independent variables used in the target leverage estimation are not restricted to the ones included in this paper. Future studies may consider other firm-specific characteristics such as manager's compensation structure and bank lines of credit (Hardin \& Hill, 2011; Sufi, 2009, Brown \& Riddiough, 2003).

Our study contributes to the academic community as the proposed theoretical model can help researchers to better understand and reconcile inconsistent findings in the literature. A reference point lies in the heart of our theoretical model. Relative leverage position and market conditions are the two integral elements in the theoretical framework. Omitting either of the two will potentially bias the estimates. For example, a positive relationship between market leverage and U.S. stock returns is documented by Bhabdari (1988) whereas a negative relationship is report by Penman et al. (2007). One of many possible reasons behind these conflicting findings is that Bhabdari (1988) uses data from 1948 to 1979, when the U.S. stock market primarily experienced rapid growth. As a result, a positive relationship between leverage and returns is found. However, the sampling period of Penman et al. (2007) (that is, 1962-2001) covers more market downturns, which may cause the relationship to be negative. Similar puzzling findings can be found in the work of George and Hwang (2010) and Penman et al. (2007) even if their sampling periods are the same. George and Hwang (2010) show a negative relationship between book leverage and returns for high-leverage subsamples, whereas the opposite is true for low-leverage subsample. However, similar results can not be found in Penman et al. (2007). Such conflicting findings are partly due to the fact that George and Hwang (2010) considers leverage position (i.e., highly leveraged or not) whereas Penman et al. (2007) does not. The explanatory power of our theoretical model is also verified by empirical evidence from the U.S. REITs market. 
Our findings also have practical implications to investors and policymakers. One interesting observation from Table 9 is that over-leveraged firms behave differently between up and down markets. Specifically, the curve for over-leveraged firms in the loss domain (or down market) is much steeper to start with, and flats out much quicker than the one in the gain domain (or up market). The shapes of curves for under-leveraged firms, however, are almost identical in the loss and gain domains (or up and down market). This predicts substantial risk-seeking behaviours among over-leveraged firms during market downturns, which results in a slow adjustment towards their target leverage. According to the causal relationship that we established in Equation (7), this will eventually hurt the firms' performance. This is consistent with the empirical findings in Sun, Titman, \& Twite (2015).

Two conclusions can be drawn from this observation. Firstly, over-leveraged REITs are particularly risky during market downturns. Investors should adjust their portfolio according to the dynamic leverage-return relationship identified in our analysis by simultaneously taking into account market condition and firm's leverage position. Secondly, policymakers should be aware of the role of debt ratio in REITs performance during crisis. Given that REITs are required to pay $90 \%$ of their taxable income as dividend, they are more likely to be deprived of cash during market downturns and rely heavily on debts to raise fund, which may exacerbate their financial distress. Government may consider some temporary dividend-breaks during such period, similar to the higher stamp duty starting threshold implemented by the UK government from 3 September 2008 to 31 December 2009. This may nudge over-leveraged REITs to reduce debt ratio and move out of the loss domain.

\section{References}

Alcock, J., Glascock, J., \& Steiner, E. (2013). Manipulation in U.S. REIT Investment Performance Evaluation: Empirical Evidence. The Journal of Real Estate Finance and Economics, 47(3), 434-465. http://doi.org/10.1007/s11146-012-9378-8

Alcock, J., Steiner, E., \& Tan, K. J. K. (2014). Joint Leverage and Maturity Choices in Real Estate Firms: The Role of the REIT Status. The Journal of Real Estate Finance and Economics, 48(1), 57-78. http://doi.org/10.1007/s11146-012-9379-7

Barberis, B. N., \& Huang, M. (2008). Stocks as Lotteries: The Implications of Probability Weighting for Security Prices. American Economic Review, 98(5), 2066-2100. 
Barberis, N. C. (2013). Thirty Years of Prospect Theory in Economics: A Review and Assessment. Journal of Economic Perspectives, 27(1), 173-196. http://doi.org/10.1257/jep.27.1.173

Barberis, N., \& Xiong, W. E. I. (2009). What Drives the Disposition Effect? An Analysis of a Long-Standing Preference-Based. The Journal of Finance, LXIV(2), 751-784.

Baucells, M., Weber, M., \& Welfens, F. (2011). Reference-Point Formation and Updating. Management Science, 57(3), 506-519. http://doi.org/10.1287/mnsc.1100.1286

Benartzi, S., \& Thaler, R. H. (1995). Myopic Loss Aversion and the Equity Premium Puzzle. The Quarterly Journal of Economics, (February), 73-92.

Bhabdari, L. C. (1988). Debt / Equity Ratio and Expected Common Stock Returns : Empirical Evidence. The Journal of Finance, 43(2), 507-528.

Blundell, R., \& Bond, S. (1998). Initial conditions and moment restrictions in dynamic panel data models. Journal of Econometrics, 87(1), 115-143. http://doi.org/10.1016/S0304-4076(98)00009-8

Boudry, W. I., Kallberg, J. G., \& Liu, C. H. (2010). An Analysis of REIT Security Issuance Decisions. Real Estate Economics, 38(1), 91-120. http://doi.org/10.1111/j.1540-6229.2009.00255.x

Boudry, W. I., Kallberg, J. G., \& Liu, C. H. (2013). Investment opportunities and share repurchases. Journal of Corporate Finance, 23, 23-38. http://doi.org/10.1016/j.jcorpfin.2013.07.006

Brown, D. T., \& Riddiough, T. J. (2003). Financing Choice and Liability Structure of Real Estate Investment Trusts. Real Estate Economics, 31(3), 313-346.

Case, B., Yang, Y., \& Yildirim, Y. (2012). Dynamic Correlations Among Asset Classes: REIT and Stock Returns. Journal of Real Estate Finance and Economics, 44, 298-318. http://doi.org/10.1007/s11146-010-9239-2

Cashman, G. D., Harrison, D. M., \& Seiler, M. J. (2013). Capital Structure and Political Risk in Asia-Pacific Real Estate Markets. The Journal of Real Estate Finance and Economics. http://doi.org/10.1007/s11146-013-9436-x

Caskey, J., Hughes, J., \& Liu, J. (2012). Leverage, excess leverage, and future returns. Review of Accounting Studies, 17(2), 443-471. http://doi.org/10.1007/s11142-011-9176-1

Chang, X. I. N., \& Dasgupta, S. (2009). Target Behavior and Financing: How Conclusive Is the Evidence? The Journal of Finance, LXIV(4), 1767-1796.

DeANGELO, H., \& Roll, R. (2015). How Stable Are Corporate Capital Structures? The Journal of Finance, LXX(1), 373-418. http://doi.org/10.1111/jofi.12163

Devos, E., Spieler, A., \& Tsang, D. (2014). Elective Stock Dividends and REITs: Evidence from the Financial Crisis. Real Estate Economics, 42(1), 33-70. 
http://doi.org/10.1111/reec.12007

Ertugrul, M., \& Giambona, E. (2010). Property Segment and REIT Capital Structure. The Journal of Real Estate Finance and Economics, 43(4), 505-526. http://doi.org/10.1007/s11146-009-9229-4

Fama, E. F., \& French, K. R. (1992). The Cross-Section of Expected Stock Returns. The Journal of Finance, XLVII(2), 427-466.

Fama, E. F., \& French, K. R. (2008). Dissecting Anomalies. The Journal of Finance, LXIII(4), 1653-1678.

Flannery, M. J., \& Hankins, K. W. (2013). Estimating dynamic panel models in corporate finance. Journal of Corporate Finance, 19, 1-19. http://doi.org/10.1016/j.jcorpfin.2012.09.004

Flannery, M. J., \& Rangan, K. P. (2006). Partial adjustment toward target capital structures. Journal of Financial Economics, 79(3), 469-506. http://doi.org/10.1016/j.jfineco.2005.03.004

Gaud, P., Jani, E., Hoesli, M., \& Bender, A. (2005). The Capital Structure of Swiss Companies: an Empirical Analysis Using Dynamic Panel Data. European Financial Management, 11(1), 51-69. http://doi.org/10.1111/j.1354-7798.2005.00275.x

George, T. J., \& Hwang, C.-Y. (2010). A resolution of the distress risk and leverage puzzles in the cross section of stock returns. Journal of Financial Economics, 96(1), 56-79. http://doi.org/10.1016/j.jfineco.2009.11.003

Glascock, J., Lu, C., \& So, R. (2000). Further evidence on the integration of REIT, bond, and stock returns. The Journal of Real Estate Finance and ..., 194, 177194. http://doi.org/10.1023/A:1007877321475

Gomes, J. F., \& Schmid, L. (2010). Levered Returns. The Journal of Finance, LXV(2), 467-495.

Graham, J. R., \& Harvey, C. R. (2001). The theory and practice of corporate finance: evidence from the field. Journal of Financial Economics, 60, 187-243.

Hardin, W. G., \& Hill, M. D. (2011). Credit Line Availability and Utilization in REITs. Journal of Real Estate Research, 33(4), 507-530.

Hardin, W. G., \& Wu, Z. (2010). Banking Relationships and REIT Capital Structure. Real Estate Economics, 38(2), 257-284.

Harrison, D. M., Panasian, C. a., \& Seiler, M. J. (2011). Further Evidence on the Capital Structure of REITs. Real Estate Economics, 39(1), 133-166. http://doi.org/10.1111/j.1540-6229.2010.00289.x

Jegadeesh, N. (1990). Evidence of Predictable Behavior of Security Returns. The Journal of Finance, XLV(3), 881-898.

Kahneman, D., \& Tversky, A. (1979). Prospect Theory: An Analysis of Decision 
under Risk. Econometrica, 47(2), 263-292.

Korteweg, A. (2010). The Net Benefits to Leverage. The Journal of Finance, LXV(6), 2137-2170.

Lemmon, M. L., Roberts, M. R., \& Zender, J. F. (2008). Back to the Beginning: Persistence and the Cross-Section of Corporate Capital Structure. The Journal of Finance, LXIII(4), 1575-1608.

Lettau, M., \& Ludvigson, S. (2001). Consumption, Aggregate Wealth, and Expected Stock Returns. Journal of Finance, 56(3), 815-849. http://doi.org/10.1111/0022-1082.00347

Lettau, M., \& Ludvigson, S. C. (2004). Understanding trend and cycle in asset values: Reevaluating the wealth effect on consumption. American Economic Review, 94(1), 276-299. http://doi.org/10.1257/000282804322970805

Livdan, D., Sapriza, H., \& Zhang, L. U. (2009). Financially Constrained Stock Returns. The Journal of Finance, LXIV(4), 1827-1862.

Lizieri, C. (2013). After the Fall: Real Estate in the Mixed-Asset Portfolio in the Aftermath of the Global Financial Crisis. Journal of Portfolio Management, 39(5), 43-59. http://doi.org/10.3905/jpm.2013.39.5.043

Modigliani, F., \& Millier, M. H. (1958). The Cost of Capital, Corporation Finance and the Theory of Investment. The American Economic Review, XLVIII(June), 261297.

Myers, S. C., \& Majluf, N. S. (1984). Corporate financing and investment decisions when firms have information that investors do not have*. Journal of Financial Economics, 13, 187-221.

Ooi, J. T. L., Ong, S. E., \& Li, L. (2010). An analysis of the financing decisions of REITs: The role of market timing and target leverage. Journal of Real Estate Finance and Economics, 40(2), 130-160. http://doi.org/10.1007/s11146-008-9127-1

Paiella, M. (2009). The stock market, housing and consumer spending: A survey of the evidence on wealth effects. Journal of Economic Surveys, 23(5), 947-973. http://doi.org/10.1111/j.1467-6419.2009.00595.x

Penman, S. H., Richardson, S. a., \& Tuna, İ. (2007). The Book-to-Price Effect in Stock Returns: Accounting for Leverage. Journal of Accounting Research, 45(2), 427-467. http://doi.org/10.1111/j.1475-679X.2007.00240.x

Striewe, N. C., Rottke, N. B., \& Zietz, J. (2013). Corporate Governance and the Leverage REITs: The Impact of the Advisor. Journal of Real Estate Research, 35(1), 103-119.

Subrahmanyam, A. (2007). Liquidity, Return and Order-Flow Linkages Between REITs and the Stock Market. Real Estate Economics, 35(3), 383-408.

Sufi, A. (2009). Bank Lines of Credit in Corporate Finance: An Empirical Analysis 
Bank Lines of Credit in Corporate Finance : An Empirical Analysis. Review of Financial Studies, 22(3), 1057-1088. http://doi.org/10.1093/rfs/hhm007

Sun, L., Titman, S. D., \& Twite, G. J. (2015). REIT and Commercial Real Estate Returns: A Postmortem of the Financial Crisis. Real Estate Economics, 43(1), 8-36. http://doi.org/10.1111/1540-6229.12055

Trigeorgis, L., \& Lambertides, N. (2014). The Role of Growth Options in Explaining Stock Returns. Journal of Financial and Quantitative Analysis, 49(3), 749-771. http://doi.org/10.1017/S0022109014000118

\section{Acknowledgement}

We are grateful for financial support from the National Natural Science Foundation of China (Project \#71231005) and the Senior Members' Research Grant from Newnham College, University of Cambridge.

\section{Appendix}

Book leverage is calculated as the book value of total debt to the book value of assets; long-term leverage is calculated as the ratio of long-term debt to the market value of assets. These alternative definitions give similar results in the estimation for target leverage in terms of the number of significant variables and the signs of coefficient estimates. The results of GMM model using the three leverage definitions are given in Table A1.

\section{[Insert Table A1 Here]}

We then re-estimate Equations (6), (7), and (8) with the target leverage estimated from the two alternative definitions of observed leverage. The results are given in Table A2. Compared with market leverage, the book leverage model provides weaker support to our hypotheses in analysis of the leverage-returns relationship. This result echoes to certain extent the inconclusive findings in the literature, where book leverage is found to be less related to firm performance (see, for example, Gomes and Schmid, 2010). Results of the long-term leverage models are consistent with those of our market leverage models. Although the number of significant coefficients is reduced in the long-term leverage model, all significant coefficient estimates are directionally consistent with the predictions based on our theoretical model. This result indicates that our findings are robust across different definitions of observed leverage.

[Insert Table A2 Here] 